\title{
Study of the diagnosis and management of ectopic pregnancy in a rural medical college and hospital
}

\section{Ravindra S. Pukale, Nadia Nishat*, Shravanthi Venkatesh}

Department of Obstetrics and Gynecology, Adichunchanagiri Hospital and Research Centre, B. G. Nagara, Karnataka, India

Received: 29 July 2021

Accepted: 01 September 2021

\section{*Correspondence:}

Dr. Nadia Nishat,

E-mail: drnadianishat@gmail.com

Copyright: ( ) the author(s), publisher and licensee Medip Academy. This is an open-access article distributed under the terms of the Creative Commons Attribution Non-Commercial License, which permits unrestricted non-commercial use, distribution, and reproduction in any medium, provided the original work is properly cited.

\section{ABSTRACT}

Background: Ectopic pregnancy is the implantation of the blastocyst elsewhere except the endometrial lining of the uterus. Ectopic pregnancy is a potentially life-threatening adverse pregnancy outcome and it requires prompt evaluation and treatment. It remains to be one of the leading causes of maternal death in the first trimester. But with better health facilities, early diagnosis and prompt treatment morbidity and mortality can be reduced.

Methods: This retrospective study was conducted over a period of 2 and a half-years from July 2018 to December 2020, in the department of obstetrics and gynaecology at Adichunchanagiri Hospital and Research Centre, B. G. Nagara, Karnataka. A total of 22 cases were admitted at our hospital during this time frame. Four modes of treatment were given according to the patient's condition, ultrasound findings and beta-human chorionic gonadotropin (hCG) levels; these were laparoscopy, laparotomy, methotrexate injection and conservative management. The outcome measures included success of each treatment modality, need for second mode of treatment in each group and duration of hospital stay. Data was collected in a preconceived format from the patient database retrospectively and analyzed.

Results: Total numbers of vaginal deliveries were 4626 during the study period. Of which $0.49 \%$ were diagnosed as ectopic pregnancy. The mean age in this study was 26.5 years. Previous history of tubectomy (22.7\%), lower segment caesarean section (13.6\%), and previous abortion/medical termination of pregnancy (18.1\%), pelvic inflammatory disease $(9.09 \%)$, previous oral contraceptive pills (OCP) use $(9.09 \%)$, and ovulation induction $(4.5 \%)$ were major contributing factors responsible for incidence of ectopic pregnancy. The pain was the most consistent presenting symptom in $90.9 \%$ of women. A classical triad of ectopic pregnancy (pain, amenorrhea and bleeding per vaginum) seen in $77.2 \%$ women. The incidence of tubal ectopic was maximum, i.e. 19 (86.4\%) cases out of 22 cases. Among tubal ectopic pregnancies, the most common site was ampulla (68.18\%). 14 (63.61\%) cases were of ruptured ectopic pregnancies. Complete salpingectomy $(50 \%)$ was done in maximum women. Salpingo oophorectomy was done in $9.09 \%$. Methotrexate was given to $22.7 \%$ of the women. No significant morbidity and mortality was found in our study among 22 patients.

Conclusions: Proper evaluation of pregnancy with associated risk factors and early diagnosis will help to preserve the tube and in turn her fertility and thus helps in decreasing morbidity and mortality.

Keywords: Ectopic pregnancy, Salpingectomy, Ultrasonography

\section{INTRODUCTION}

An ectopic pregnancy occurs when a fertilized ovum implants outside the normal uterine cavity. ${ }^{1}$ Ectopic gestation is a result of a flaw in the reproductive physiology of the human body which ultimately results in the death of the foetus. ${ }^{2}$ Worldwide, ectopic pregnancy complicates $0.25-2.0 \%$ of all pregnancies. It is the most 
common cause of maternal morbidity and mortality in the first trimester. Without timely diagnosis and treatment it can lead to a life-threatening situation resulting in affecting her fertility unavoidably by causing mutilation of the fallopian tubes, ovary and sometimes even the uterus. ${ }^{3}$ Patients with an ectopic pregnancy commonly present with pain and vaginal bleeding between 6 and 10 weeks' gestation. ${ }^{1}$

The diagnosis of ectopic pregnancy has become more frequent during the last decades but the incidence of ruptured ectopic pregnancy has declined. This is due to increased use of quantitative beta human chorionic gonadotropin $(\beta-\mathrm{hCG})$ measurements, minimally invasive surgery and transvaginal ultrasonography in the management of ectopic pregnancy. ${ }^{4}$ Blood levels of $\beta$ hCG are useful in both diagnosis and planning of management. Serum value of $1500 \beta$-hCG and absent intrauterine gestational sac strongly suggests ectopic pregnancy. Doubling $\beta$-hCG in 48 hours is seen in normal intrauterine pregnancy and failure of doubling may indicate ectopic pregnancy. If $\beta-\mathrm{hCG}$ is less than 5000, the success of medical management is high. If the value is less than 1000 the success of expectant management is high. $^{6}$

Transabdominal or transvaginal sonography may show the presence of an adnexal mass with or without the presence of gestation sac and cardiac activity and an empty endometrial cavity strongly indicating the diagnosis of ectopic pregnancy. Rarely, it can be seen at the lower part of the uterus at the scar site or in the cervix with empty endometrial cavity in cervical or scar site ectopic pregnancies also. The presence of ring of fire sign and increased vascularity around ectopic gestational sac in colour Doppler is also a significant finding. Presence of free fluid in the abdomen and its quantification may be able to predict rupture of ectopic pregnancy. ${ }^{6}$

Diagnostic laparoscopy is the gold standard investigation if the ultrasound is found to be inconclusive. In some of the cases of pregnancy of unknown location, a dilatation and curettage can be useful when performed with a negative diagnostic laparoscopy for suspected ectopic pregnancy. The absence of chorionic villi, in the presence of a raised $\beta$-hCG level is suggestive of ectopic pregnancy.

Early diagnosis decreases the risk of tubal rupture and allows a more conservative medical treatments to be employed..$^{5}$ Medical management is opted if patients are hemodynamically stable, size of the adnexal mass is less than $3.5 \mathrm{~cm}$, with absence of cardiac activity and if $\beta$-hCG level is less than 5000. This includes injection of methotrexate intramuscularly $1 \mathrm{mg} / \mathrm{kg}$ body weight on day $1,3,5,7\left(50 \mathrm{mg} / \mathrm{m}^{2}\right)$ multidose regimen upto maximum 4 doses with leucovorin rescue $0.1 \mathrm{mg} / \mathrm{kg}$ on days $2,4,6,8$ or a single dose regimen of injection methotrexate. Expectant management can be used in stable patients where $\beta$-hCG levels are less than 1500 , and steadily decreasing and the patient is willing for follow-up. Surgical management includes salpingectomy, salpingotomy and tubal milking. Laparoscopic approach is preferred to an open approach in patients who are hemodynamically stable. Laparotomy is done in patients presenting with hemoperitoneum and hypovolemic shock. This retrospective study and analysis was done to determine the incidence, clinical features, risk factors, treatment, and morbidity and mortality associated with ectopic pregnancy in a rural medical college.

\section{METHODS}

This retrospective study was conducted over a period of 2 and a half years from July 2018 to 31 December 2020 in the department of obstetrics and gynecology at Adichunchanagiri Hospital and Research Centre, B. G. Nagara, Karnataka. During the study period all known cases of ectopic pregnancy were evaluated. The data of patients with ectopic pregnancy were traced through the patient database. Data are expressed as percentages in the text and tables. Information regarding total number of deliveries during study period, details of demographic characteristics, presenting clinical symptoms and signs, parity, use of contraception, diagnostic tools used, obstetric history, risk factors for ectopic pregnancy, site of ectopic pregnancy, line of management as well as morbidity and mortality were obtained. The diagnostic tools were clinical diagnosis, urine pregnancy test (UPT), $\beta$-hCG titer and trans-vaginal ultrasound. Based on thorough evaluation, type of management was decided.

\section{Inclusion criteria}

All women with confirmed clinical diagnosis of ectopic pregnancy were included in the study.

\section{Exclusion criteria}

There was no exclusion criteria.

Information was recorded in a present proforma, data was entered in Microsoft (MS) excel spreadsheet and analyzed. Continuous variables data were calculated as mean \pm standard deviation (SD) and categorical variable data was compiled as frequency and percentage.

\section{RESULTS}

During the study period total 4626 deliveries occurred in the department of obstetrics and gynecology. Out of these 22 patients were diagnosed as ectopic pregnancies. The incidence of ectopic pregnancy was $0.48 \%$. In this study the highest incidence was seen in the 21 to 30 years age group and majority of patients $68.18 \%$ were multigravida (Table 1). $81.8 \%$ presented as acute abdomen whereas $19.1 \%$ presented as chronic cases.

UPT was positive in all cases. Ultrasonography (USG) helped in $90.9 \%$ cases in diagnosing ectopic pregnancy. 
Gestational age ranged between 3 weeks 3 days to 14 weeks 2 days, and the most frequent gestational age was around 6-8 weeks.

Table 1: Baseline characteristics.

\begin{tabular}{|c|c|c|}
\hline $\begin{array}{l}\text { Baseline } \\
\text { characteristics }\end{array}$ & $\begin{array}{l}\text { No. of } \\
\text { patients }\end{array}$ & Percentage \\
\hline \multicolumn{3}{|l|}{ Age group } \\
\hline$<20$ & 1 & 4.54 \\
\hline $21-25$ & 5 & 22.72 \\
\hline $26-30$ & 10 & 45.45 \\
\hline $31-35$ & 6 & 27.27 \\
\hline \multicolumn{3}{|l|}{ Gravida } \\
\hline 1 & 7 & 31.81 \\
\hline 2 & 6 & 27.27 \\
\hline 3 & 6 & 27.27 \\
\hline 4 & 1 & 4.54 \\
\hline 5 & 2 & 9.09 \\
\hline \multicolumn{3}{|l|}{ Parity } \\
\hline Primi & 5 & 22.72 \\
\hline Multi & 8 & 36.36 \\
\hline \multicolumn{3}{|c|}{ Presentation acute/ chronic } \\
\hline Acute & 18 & 81.81 \\
\hline Chronic & 4 & 18.18 \\
\hline \multicolumn{3}{|l|}{ Symptoms } \\
\hline Pain abdomen & 20 & 90.90 \\
\hline Bleeding pv & 9 & 40.90 \\
\hline Amenorrhea & 10 & 45.45 \\
\hline Vomiting & 9 & 40.90 \\
\hline Syncope/fainting & 2 & 9.09 \\
\hline Classic triad & 9 & 40.90 \\
\hline Asymptomatic & 1 & 4.54 \\
\hline \multicolumn{3}{|l|}{ Triad } \\
\hline \multicolumn{3}{|l|}{ Signs } \\
\hline Abdominal tenderness & 18 & 81.81 \\
\hline Abdominal distension & 1 & 4.54 \\
\hline $\begin{array}{l}\text { Cervical motion } \\
\text { tenderness }\end{array}$ & 12 & 54.54 \\
\hline Forniceal fullness & 9 & 40.90 \\
\hline \multicolumn{3}{|l|}{ Hemodynamics } \\
\hline Stable & 13 & 59.09 \\
\hline Tachycardia & 7 & 31.81 \\
\hline Shock & 2 & 9.09 \\
\hline
\end{tabular}

Table 2: Risk factors.

\begin{tabular}{|l|l|l|}
\hline Risk factors & No. of cases & Percentage \\
\hline $\begin{array}{l}\text { Abdominal/pelvic } \\
\text { surgery }\end{array}$ & 5 & 22.72 \\
\hline LSCS & 3 & 13.63 \\
\hline Ovulation induction & 1 & 4.54 \\
\hline PID & 2 & 9.09 \\
\hline OCP & 2 & 9.09 \\
\hline Previous abortion & 4 & 18.18 \\
\hline
\end{tabular}

A total $40.9 \%$ patients presented with classic triad of amenorrhea, pain and bleeding. The commonest symptom was pain present in nearly $90.09 \%$ of patients. The mean gestational age at the time of diagnosis was $7.5 \pm 1$ weeks.

Table 3: Incidence as per site of ectopic pregnancy.

\begin{tabular}{|lll|}
\hline Site of pregnancy & $\begin{array}{l}\text { No. of } \\
\text { patients }\end{array}$ & Percentage \\
\hline Ampullary & 15 & 68.18 \\
\hline Isthmus & 3 & 13.63 \\
\hline Fimbrial & 1 & 4.54 \\
\hline Tubal abortion & 2 & 9.09 \\
\hline Scar ectopic & 1 & 4.54 \\
\hline
\end{tabular}

Table 4: Per operative findings in ectopic pregnancy.

\begin{tabular}{|lll|}
\hline Per operative findings & $\begin{array}{l}\text { No. of } \\
\text { patients }\end{array}$ & Percentage \\
\hline Ruptured & 12 & 54.54 \\
\hline Unruptured & 8 & 36.36 \\
\hline Tubal abortion & 2 & 9.09 \\
\hline
\end{tabular}

Table 5: Types of treatment modalities offered to the patient.

\begin{tabular}{|lll|}
\hline Treatment modality & $\begin{array}{l}\text { No. of } \\
\text { patients }\end{array}$ & Percentage \\
\hline Laparotomy & 16 & 72.72 \\
\hline Laparoscopy & 2 & 9.09 \\
\hline Medical & 3 & 13.63 \\
\hline Expectant & 1 & 4.54 \\
\hline Medical f/b surgical & 2 & 9.09 \\
\hline
\end{tabular}

Table 6: Types of surgeries.

\begin{tabular}{|l|l|l|}
\hline Type of surgery & $\begin{array}{l}\text { No. of } \\
\text { patients }\end{array}$ & Percentage \\
\hline $\begin{array}{l}\text { Laparoscopic } \\
\text { salpingectomy }\end{array}$ & 2 & 9.09 \\
\hline Salpingectomy & 12 & 54.54 \\
\hline Salpingo oophorectomy & 3 & 13.63 \\
\hline $\begin{array}{l}\text { Resection of ectopic } \\
\text { with uterine scar repair }\end{array}$ & 1 & 4.54 \\
\hline
\end{tabular}

Pallor was present in $59.09 \%$ cases. $9.09 \%$ patients presented with shock whereas $27.7 \%$ had only tachycardia and rest were with stable vitals. The commonest clinical sign was adnexal tenderness. Urine pregnancy test was positive in $100 \%$ of patients. The diagnosis was confirmed on ultrasound with adnexal mass present in $95.1 \%$ of cases and empty uterine cavity in $95.1 \%$ of patients. Free fluid was present in $81.81 \%$ cases. The commonest site of ectopic pregnancy was fallopian tube in which ampullary accounted for $68.18 \%$ of patients. On per operative findings rupture was present in $54.54 \%$ cases $9.09 \%$ tubal abortion with $36.36 \%$ as unruptured cases (Table 3 ). 
A total 19 patients were managed surgically out of which 16 had laparotomy and 2 had laparoscopy. Preoperatively culdocentesis was done in three patients where USG was not able to diagnose rupture with presence of free fluid. Three patients were given medical management; two patients required surgical management after failed medical management, and one patient was followed with expectant management due to $\beta$-hCG less than 500 and falling trends there on. One patient of scar site ectopic pregnancy was managed surgically with resection of ectopic with uterine scar repair. Salpingectomy was done in 14 cases and salpingo oophorectomy was done in 3 cases where generalized oozing was present, and haemostasis was difficult to achieve. In one patient with USG finding of adnexal mass and intraoperative equivocal findings, dilatation and curettage (D\&C) was done in one patient on table to confirm endometrial changes in the absence of intrauterine gestation.

No mortality and acute renal failure were found in our study among 22 patients which gives information that early diagnosis and treatment can prevent significant morbidity and mortality in ruptured ectopic pregnancy.

\section{DISCUSSION}

The incidence of ectopic pregnancy was found to be $0.48 \%$ in our study comparable to Thonneau et al. ${ }^{7}$ The incidence is less compared to $1.8 \%$ of Prasanna et al and $1.7 \%$ of Ara et al. ${ }^{8,9}$ Incidence of reported ectopic pregnancies vary worldwide as reported by various studies.

Identifiable risk factors were present in $77.27 \%$ comparable to a study by Prasanna et al $(80 \%) .{ }^{9}$ In the present study, $18 \%$ had previous abortions comparable to Prasanna et al. ${ }^{9}$ Prior abortions lead to postabortal infections leading to tubal damage. In the past, these were due to illegal abortions which were not done under aseptic precautions and lack of proper antibiotic coverage.

$4.5 \%$ of the study was infertile and had undergone ovulation induction. The association between infertility, previous pelvic infection and tubal pathology is a possible explanation.

In our study $22.7 \%$ had undergone tubal sterilisation. Improper surgical technique and formation of peritubal fistulas can lead to ectopic pregnancy. In the postpartum period, edematous congested and friable tubes lead to incomplete tubal occlusion resulting in ectopic pregnancy.

$4.5 \%$ of the study had previous intrauterine contraceptive device (IUCD) use. IUCD does not prevent ovulation and prevents intrauterine pregnancy but not tubal and ovarian pregnancy.
Incidence in the age group was found to be $68.18 \%$ between the ages 26-30 years, comparable to Paramar et al $(69 \%) .{ }^{10}$ Highest incidence was seen between the age 26-30 years, because most Indian women marry and completes their family at an early age so these are the peak reproductive years in which women are exposed to sexually transmitted diseases (STDs), abortion, sepsis in the puerperium.

Multigravida were found to be maximum $68.18 \%$ comparable to Paramar et al $(68.15 \%){ }^{10}$ The higher incidence in multigravidae may be due to previous miscarriages or infections resulting in tubal damage.

In the present study group pelvic inflammatory disease (PID) was present in $9.09 \%$ of the patients. Endosalpingitis leads to mucosal damage and entrapment of the migrating embryo and exosalpingitis may lead to peritubal adhesions which may impair peristaltic movements leading to inadequate transportation.

Pain abdomen was found in $90 \%$ comparable to $90 \%$ in Prasanna et al. ${ }^{9}$ Amenorrhea was seen in $45.5 \%$ and bleeding pervagina was seen in $40.9 \%$ of the study group.

Tachycardia in $27.7 \%$ of patient comparable to $23.7 \%$ in Ara et al. ${ }^{8}$ Pallor was present in $59.09 \%$ of the cases comparable to Ara et al $(62 \%) .{ }^{8}$ Preexisting anemia with superimposed significant acute blood loss can explain the higher incidence of pallor in ruptured ectopic pregnancy.

Shock was seen in $9.09 \%$ of the study group. Access to healthcare is good in the vicinity which explains most patients being hemodynamically stable when they first arrive. Hypovolemia and decompensation with shock indicates significant intraperitoneal hemorrhage. $81.81 \%$ of the study group presented as acute cases comparable to Ara et al $(85.1 \%){ }^{8}$

Diagnosis confirmed by USG by presence of adnexal mass in $95.1 \%$ of cases comparable to Ara et al $(98.7 \%){ }^{8}$ Free fluid was present in $81.81 \%$ of cases comparable to Ara et al $(84.7 \%){ }^{8}$ Most common site of ectopic was tubal $(86.36 \%)$. Ampullary region $(68.18 \%)$ was most commonly involved, followed by isthmic $(13.63 \%)$ and fimbrial $(4.5 \%)$.

Right sided ectopic were more common (63.6\%) comparable to Paramar et al (58.9\%). ${ }^{10}$ Tubal abortions were seen in $9.09 \%$ of the cases. Ruptured ectopic was found in $54.5 \%$ and unruptured ectopic was seen in $36.36 \%$ of the cases.

Salpingectomy was the most common procedure $63.36 \%$, salpingo oophorectomy in $13.63 \%$ and methotrexate in $13.63 \%$ comparable to Paramar et al $(71 \%, 10 \%, 15 \%) .{ }^{10}$ $9.09 \%$ underwent laparoscopic salpingectomy and $54.54 \%$ underwent exploratory laparotomy. 
In the present study, there is one case of lower segment cesarian section (LSCS) scar site ectopic pregnancy for which resection of ectopic with repair of uterine scar was done. As the incidence of LSCS deliveries are increasing the incidence of scar site ectopic pregnancies is also showing an increase. The vascularity of this fibrotic scar is poor and it may lead to spontaneous failure of the pregnancy and the chance of success of systemic injection of methotrexate is very poor in these patients due to decreased vascularity. Such pregnancies may sometimes result in torrential hemorrhage due to scar dehiscence or rupture of scar site and this necessitates laparotomy.

Blood transfusion was required in $68.18 \%$ majority, one unit comparable to Ara et al. ${ }^{8} 31.82 \%$ had to undergo operative intervention under general anesthesia. $18.18 \%$ of the study group had an extended hospital stay more than 10 days. There was fortunately no wound sepsis, or hysterectomy, or intensive care unit (ICU) admission required or any mortality in the study group.

\section{CONCLUSION}

Ectopic pregnancy is one of the leading causes of maternal morbidity and mortality in the first trimester of pregnancy. In the present study though there was no mortality, but a large number of patients required blood transfusion and open surgeries. Surgery both laparotomy and laparoscopy still remains the main treatment modality based on the patient's condition. Early detection means that conservative options can be considered in haemodynamically stable patients. Ultrasonography is the main imaging modality and a useful adjunct to clinical diagnosis. Previous histories of abortion, pelvic infections, infertility, OCP, IUCD, abdominal and tubal surgery were some of the identifiable risk factors for ectopic pregnancy.

Funding: No funding sources Conflict of interest: None declared

Ethical approval: The study was approved by the Institutional Ethics Committee

\section{REFERENCES}

1. Walker JJ. Ectopic pregnancy. Clin Obstet Gynecol. 2007;50:89-99.

2. Gary CF, Leveno KJ, Bloom SL, Hauth JC, Rouse DJ, Spong CY. Williams Obstetrics. Ectopic pregnancy. 23rd edition. The McGraw-Hill Companies. 2010;238-54.

3. Centers for Disease Control and Prevention (CDC). Ectopic pregnancy--United States, 1990-1992. MMWR Morb Mortal Wkly Rep. 1995;44(3):46-8.

4. Timmerman D. Predictive models for the early diagnosis of ectopic pregnancy. Verh $\mathrm{K}$ Acad Geneeskd Belg. 2004;66(2):155-71.

5. Barnhart KT. Clinical practice. Ectopic pregnancy. N Engl J Med. 2009;361:379-87.

6. National Institute of Clinical Excellence. Ectopic pregnancy and miscarriage. Manchester: NICE. 2019. Available at: https://www.nice.org.uk/guidance/ng126/resources/ ectopic-pregnancy-andmiscarriage-diagnosis-andinitial-management-pdf-66141662244037. Accessed on 17 July 2021.

7. Thonneau P, Hijazi Y, Goyaux N, Calvez T, Keita N. Ectopic pregnancy in Conakry, Guinea. Bull World Health Organ. 2002;80:365-70.

8. Ara A, Chawla I, Agarwal R, Manjhi B. Clinical study on presentation and management of ectopic pregnancies in a tertiary care centre. Int $\mathbf{J}$ Reprod Contracept Obstet Gynecol. 2020;9:173-8.

9. Prasanna B, Jhansi CB, Swathi K, Shaik MV. A study on risk factors and clinical presentation of ectopic pregnancy in women attending a tertiary care centre. IAIM. 2016;3(1):90-6.

10. Parmar S, Sharma N, Dhakar V. Ectopic pregnancy: an observational study in a tertiary care centre of Southern Rajasthan. Int J Reprod Contracept Obstet Gynecol. 2020;9.

Cite this article as: Pukale RS, Nishat N, Venkatesh S. Study of the diagnosis and management of ectopic pregnancy in a rural medical college and hospital. Int J Reprod Contracept Obstet Gynecol 2021;10:428791. 